\title{
Sistem Informasi Persediaan Barang Menggunakan Unified Software Development Process Pada Toko Alat Kesehatan
}

\author{
Ratih Yulia Hayuningtyas \\ Teknik Informatika STMIK Nusa Mandiri Jakarta \\ Ratih.winziy@gmail.com
}

\begin{abstract}
Information system is very important for a company in carrying out operational activities. Information system be supported by information technology such as computer that used in data processing that will produce an information. Computers are needed in a company one of which is a trading company, where every activity of goods in and out required recording of goods. Manual recording of goods is often mistaken or human error, such as recording that is incompatible with incoming and outgoing goods, error ini checking stock, less efficient and inaccurate inventory data in search and delay in reporting inventory. To overcome this problem required a program that support the inventory system using Unified Software Development Porcess.
\end{abstract}

Keywords: USDP, Information System Inventory

Abstrak - Sistem informasi saat ini sangat penting untuk suatu perusahaan dalam menjalankan kegiatan operasional. Sistem informasi harus ditunjang dengan teknologi informasi seperti pemanfaatan komputer yang digunakan dalam pengolahan data yang akan menghasilkan suatu informasi. Komputer sangat diperlukan pada suatu perusahaan salah satunya yaitu perusahaan dagang, dimana setiap kegiatan barang masuk dan keluar diperlukan pencatatan barang. Pencatatan barang yang dilakukan secara manual sering terjadi kesalahan atau human error, seperti pencatatan yang tidak sesuai dengan barang yang masuk dan keluar, kesalahan dalam pengecekan stok, kurang efisien dan tidak akuratnya data persediaan dalam pencarian serta keterlambatan dalam pelaporan persediaan barang. Untuk mengatasi masalah ini diperlukan suatu program yang mendukung sistem persediaan menggunakan Unified Software Development Process.

Kata Kunci: USDP, Sistem Informasi Persediaan

\section{A. PENDAHULUAN}

Persediaan merupakan hal yang paling penting bagi perusahaan, terutama untuk perusahaan dagang. Setiap menjalankan kegiatan operasional selalu mencatat barang masuk dan barang keluar.

Setiap transaksi yang terjadi diperusahaan dagang selalu melakukan pencatatan barang masuk dan barang keluar. Pada toko alat kesehatan kegiatan operasional setiap hari yaitu melakukan penjualan alat kesehatan kepada customer dan melakukan pembelian kepada supplier. Aktifitas pembelian dan penjualan sangat berpengaruh terhadap persediaan barang dimana setiap pencatatan tidak lepas dari kesalahan atau human error. Kesalahan yang sering terjadi yaitu pencatatan data barang masuk atau barang keluar tidak sesuai dengan jumlah barang yang masuk dan barang yang keluar pada setiap transaksi.

Selain itu terjadinya kesalahan dalam pengecekan stok barang yang masuk atau barang keluar pada saat pencatatan stok akhir (Minarni \& Susanti, 2014). Pencarian data barang tidak efisien dan tidak akuratnya data persediaan barang, dan keterlambatan dalam pelaporan persediaan barang (Sari \& Nuari, 2017).

Sistem Informasi saat ini sangat penting bagi suatu perusahaan, karena sangat membantu perusahaan dalam menjalankan kegiatan operasional. Sistem Informasi perlu ditunjang dengan teknologi informasi yaitu pemanfaatan komputer sebagai alat untuk mempercepat pendistribusian data dan informasi (Rahadi, 2014). Sistem yang sudah terkomputerisasi diharapkan mampu mengatasi kendala yang dihadapi saat masih menggunakan sistem manual (Darwati, 2018). Sistem komputerisasi sangat cocok diterapkan untuk persediaan barang dalam mengatasi permasalahan yang ada.

Penelitian ini bertujuan untuk menghasilkan program persediaan barang untuk mengatasi permasalahan yang dapat melakukan kontrol persediaan barang, sehingga barang masuk dan barang keluar dapat diketahui dengan jelas tanpa adanya kesalahan.

\section{B. TINJAUAN PUSTAKA}

\section{Sistem}

Sistem dapat diartikan sebagai kesatuan dari bagian-bagian yang saling berkaitan untuk menghasilkan informasi dan tercapainya suatu tujuan.

2. Informasi

Informasi merupakan sekumpulan data atau fakta yang ada dan diolah untuk menghasilkan sebuah informasi yang dibutuhkan oleh penerima/pengguna.

\section{Persediaan}

Bagian yang disediakan dalam proses yang terdapat dalam suatu perusahaan untuk 
diproduksi, serta barang jadi yang disediakan untuk memenuhi permintaan dari konsumen setiap waktu yang disimpan dan dirawat menurut aturan tertentu dalam keadaan siap pakai dan tersimpan dalam database (MT \& Poerwanta, 2013)

4. Unified Modeling Language (UML)

Standar bahasa yang banyak digunakan di dunia industri untuk mendefinisikan requirement, membuat analisis dan desain, serta menggambarkan arsitektur dalam pemrograman berorientasi objek (Sukamto \& Shalahuddin, 2016).

5. Entity Relationship Diagram (ERD)

Entity Relationship Diagram merupakan gambaran tentang relasi dari setiap entity atribut dari file yang digunakan untuk menggabungkan atau menghubungkan data sehingga dapat dirancang laporan atau input data yang diinginkan (Veza \& Ropianto, 2017)

\section{c. METODE PENELITIAN}

Metode pengumpulan data yang digunakan dalam penelitian ini yaitu:

1. Observasi, pada tahap ini dilakukan kunjungan ke toko alat kesehatan untuk mengumpulkan data yang digunakan dalam penelitian ini.

2. Literatur, dengan mempelajari dan memahami buku-buku, jurnal-jurnal dan referensi lainnya terkait dengan penelitian ini.

Metodologi pengembangan perangkat lunak menggunakan model Unified Software Development Process metodologi ini bersifat use-case-driven. Tahapan dari Unified Software Development Process dapat dilihat pada gambar dibawah ini.

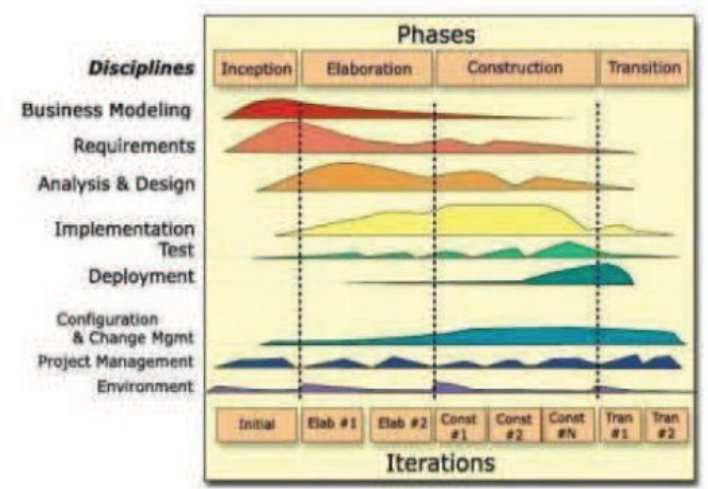

Sumber: (Nugroho, 2010)

\section{Gambar I Phase Unified Software \\ Development Process}

\section{HASIL DAN PEMBAHASAN}

Melihat permasalahan yang ada selanjutnya adalah mengimplementasikan ke

a. Use Case Diagram

Gambar II merupakan rancangan sistem yang akan dibuat pada sistem informasi persediaan
Metode pengembangan perangkat lunak dengan Unified Software Development Process yang memiliki 4 tahapan, sebagai berikut:

1. Inception

Pada tahapan ini mendeskripsikan kebutuhan-kebutuhan sistem yang hendak dibuat.

\section{Analisa kebutuhan bagian Gudang}

a. Dapat mengelola form data barang

b. Dapat mengelola form purchasing request

c. Dapat mengelola form goods receipt

d. Dapat mengelola form invoice

Analisa kebutuhan bagian pembelian

a. Dapat mengelola form purchase order Analisa kebutuhan bagian penjualan

a. Dapat mengelola form sales order

2. Elaboration

Pada tahapan elaboration sudah memulai membangun rancangan perangkat lunak yang sesuai dengan kebutuhan yang sudah dideskripsikan di tahapan inception. Rancangan yang akan dibuat dari UML, dan Basis Data. Berikut adalah gambar use case diagram dan rancangan basis data berupa erd pada sistem informasi persediaan yang akan dibuat: 


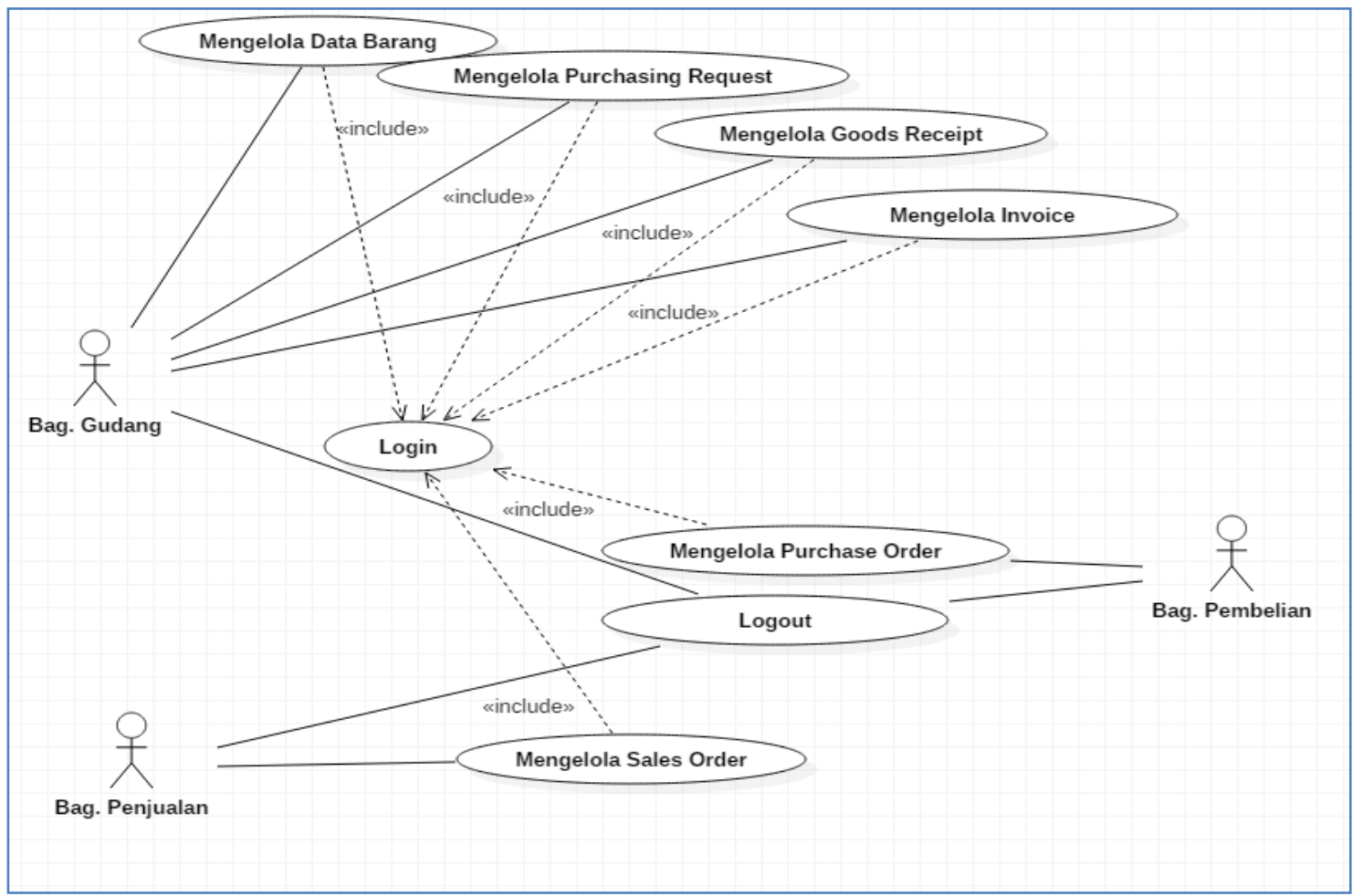

Gambar.II Usecase Diagram

b. Basis Data

Gambar. III merupakan gambar entity relationship diagram pada sistem informasi persediaan

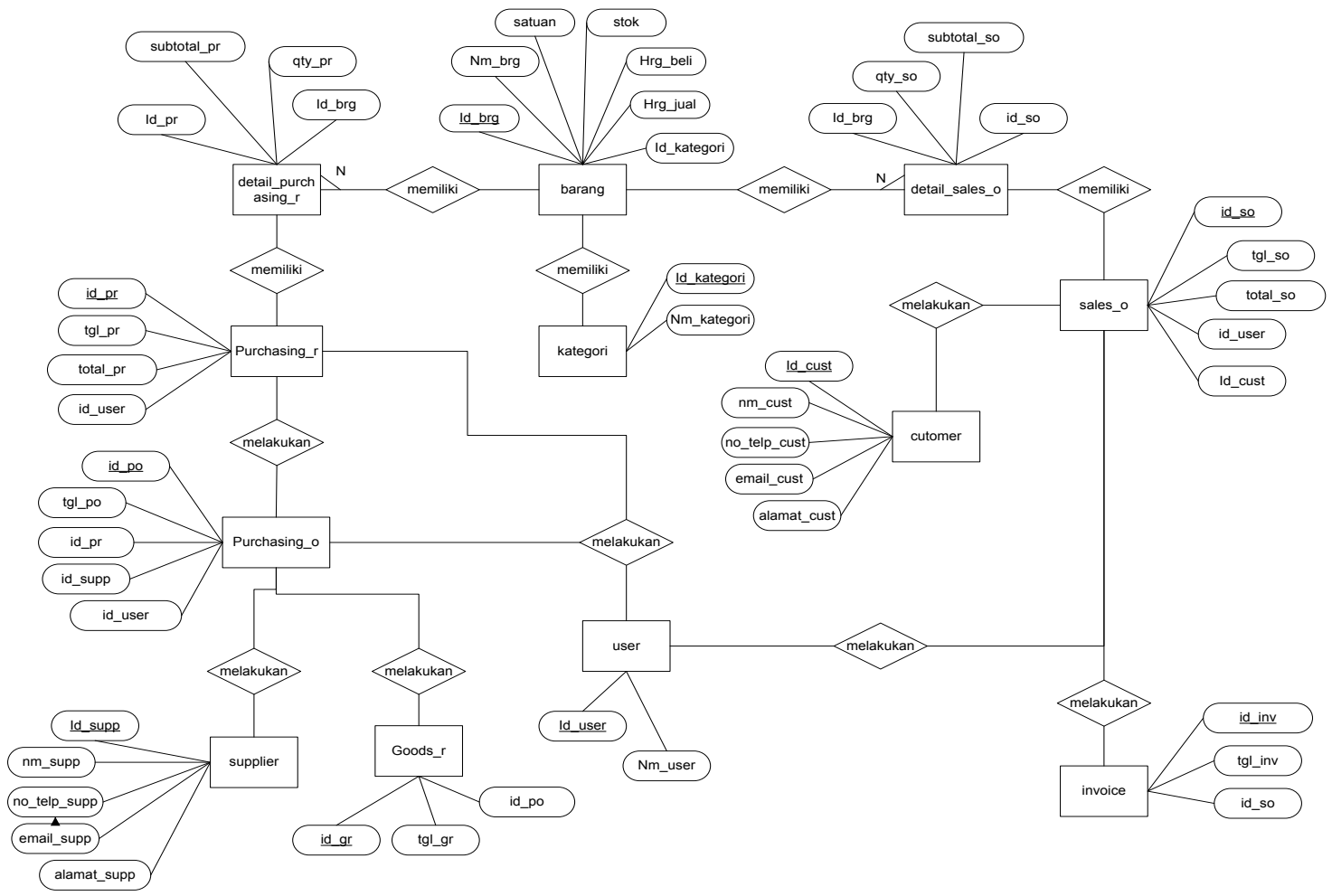

Gambar.III Entity Relationship Diagram 
3. Construction

Tahapan construction perangkat lunak sudah siap digunakan yang sesuai dengan kebutuhan pengguna. Berikut adalah rancangan sistem informasi persediaan.

a. Form Barang

Form barang digunakan untuk memasukan semua data barang yang ada diperusahaan. Berikut gambar form barang dapat dilihat dibawah ini.

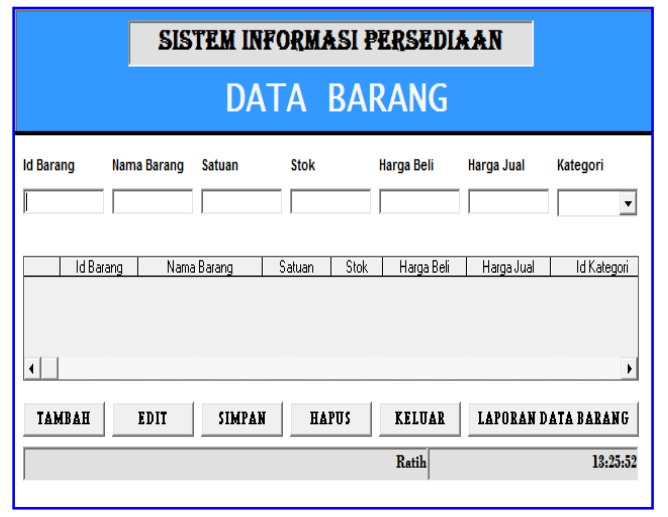

Gambar IV. Form Barang

\section{b. Form Purchasing Request}

Form Purchasing Request digunakan untuk melakukan pemesanan barang, apabila persediaan barang habis atau menipis. Berikut adalah gambar form purchasing request.

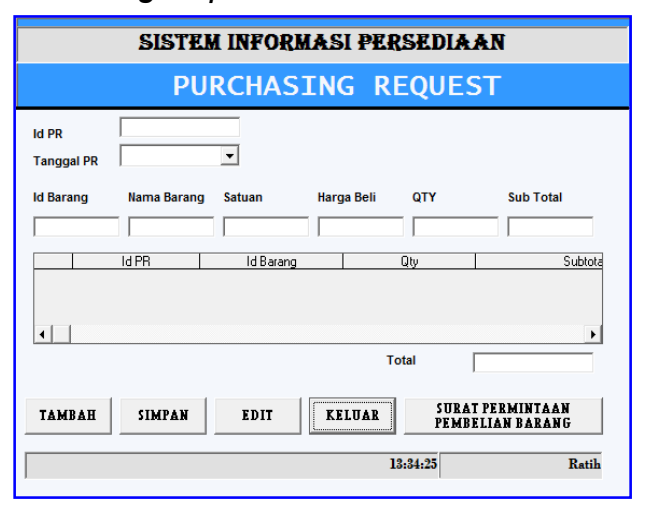

Gambar V. Form Purchasing Request

\section{c. Form Purchasing Order}

Form Purchasing Order digunakan untuk melakukan pembelian barang ke supplier. Berikut adalah gambar form purchasing order.

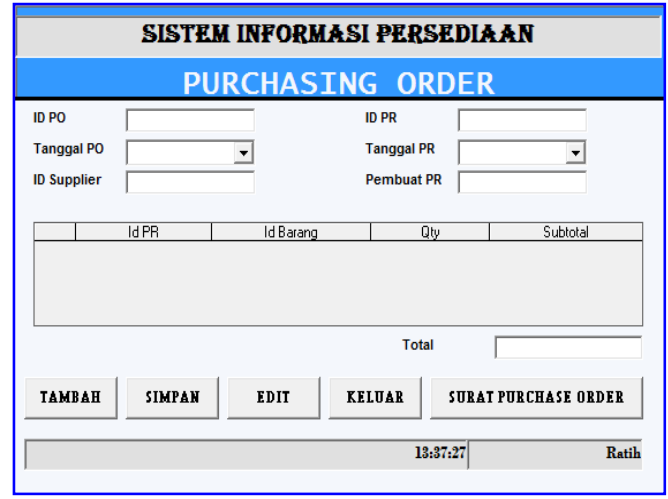

Gambar VI. Form Purchasing Order

\section{d. Form Goods Receipt}

Form Goods Receipt digunakan untuk memasukan data barang yang sudah diterima dari supplier.

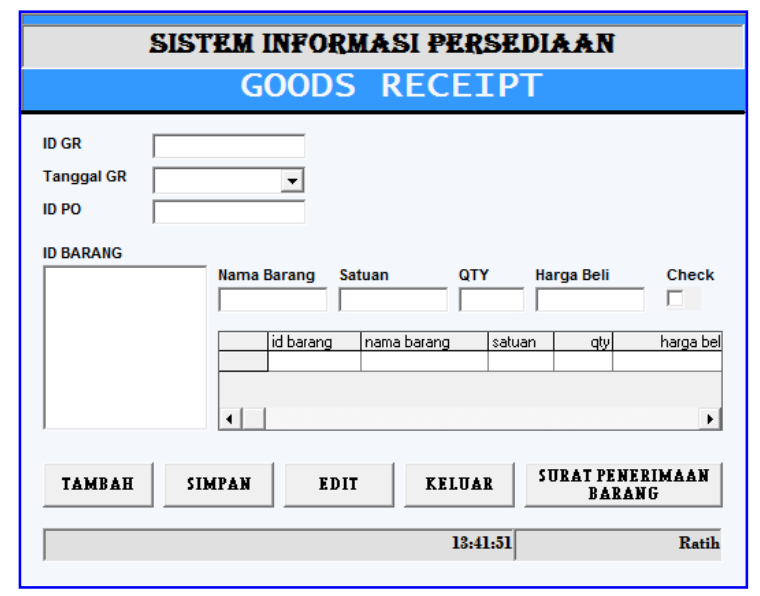

Gambar VII. Form Goods Receipt

\section{e. Form Sales Order}

Form Sales Order digunakan pada saat ada penjualan barang kepada customer.

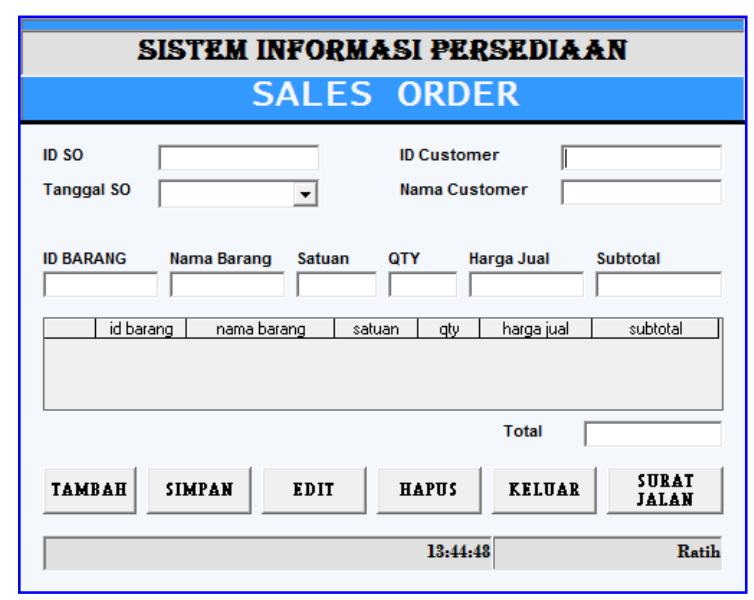

Gambar VIII. Form Sales Order 
f. Form Invoice

Form Invoice digunakan untuk mencatat barang keluar yang ada digudang karena ada transaksi penjualan.

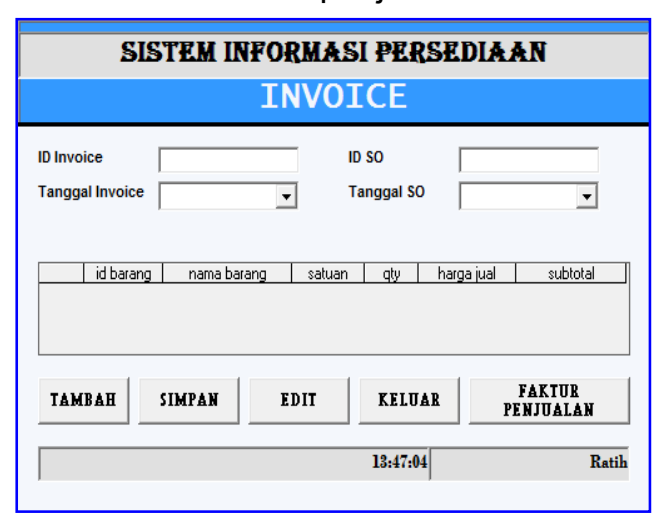

Gambar IX. Form Invoice

\section{Transition}

Tahapan ini akan dilakukan pengujian sistem oleh pengguna. Berikut adalah pengujian terhadap form purchasing order.

Tabel 1. Pengujian form purchasing order

\begin{tabular}{|c|c|c|c|c|c|}
\hline No & $\begin{array}{l}\text { Skenario } \\
\text { Pengujian }\end{array}$ & Test Case & $\begin{array}{l}\text { Hasil yang } \\
\text { Diharapkan }\end{array}$ & $\begin{array}{l}\text { Hasil } \\
\text { Pengujian }\end{array}$ & Kesimpulan \\
\hline 1 & $\begin{array}{l}\text { Form purchasing } \\
\text { order dijalankan }\end{array}$ & $\begin{array}{l}\text { Tampil jam } \\
\text { dan nama } \\
\text { user }\end{array}$ & $\begin{array}{l}\text { Tampil jam dan } \\
\text { nama user secara } \\
\text { otomatis saat form } \\
\text { purchasing } \\
\text { dijalankan }\end{array}$ & $\begin{array}{l}\text { Sesuai } \\
\text { harapan }\end{array}$ & Valid \\
\hline 2 & Klik tombol tambah & Tampil id po & $\begin{array}{l}\text { Tampil id pod an } \\
\text { tanggl po, id supplier, } \\
\text { id pr, tanggal pr, } \\
\text { nama pembuat pr } \\
\text { kosong }\end{array}$ & $\begin{array}{l}\text { Sesuai } \\
\text { harapan }\end{array}$ & Valid \\
\hline 3 & $\begin{array}{l}\text { Pilih tanggal po } \\
\text { (purchasing order) }\end{array}$ & $\begin{array}{l}\text { Tampil } \\
\text { tanggal po }\end{array}$ & $\begin{array}{l}\text { Menampilkan tanggal } \\
\text { po sesuai dengan } \\
\text { transaksi }\end{array}$ & $\begin{array}{l}\text { Sesuai } \\
\text { harapan }\end{array}$ & Valid \\
\hline 4 & $\begin{array}{l}\text { Masukkan } \\
\text { supplier }\end{array}$ & $\begin{array}{l}\text { Tampil id } \\
\text { supplier }\end{array}$ & $\begin{array}{lr}\text { Pada } & \text { saat } \\
\text { memasukkan id } & \text { id } \\
\text { supplier aan tampil } \\
\text { pesan jika id supplier } \\
\text { benar, jika salah } \\
\text { maka aan } \\
\text { menampilkan pesan } \\
\text { id supplier salah } \\
\end{array}$ & $\begin{array}{l}\text { Sesuai } \\
\text { harapan }\end{array}$ & Valid \\
\hline 5 & $\begin{array}{l}\text { Masukkan id pr } \\
\text { (purchasing } \\
\text { request) }\end{array}$ & $\begin{array}{l}\text { Tampil id pr, } \\
\text { tanggal pr, } \\
\text { nama } \\
\text { pembuat pr, } \\
\text { dan data } \\
\text { barang yang } \\
\text { dipesan }\end{array}$ & $\begin{array}{l}\text { Pada saat meengisi } \\
\text { id pr jika benar maka } \\
\text { akan tampil tanggal } \\
\mathrm{pr} \text {, nama pembuat } \\
\mathrm{pr} \text {, dan data barang } \\
\text { yang ada di } \\
\text { purchasing request } \\
\text { untuk melakukan } \\
\text { pembelian barang ke } \\
\text { supllier }\end{array}$ & $\begin{array}{l}\text { Sesuai } \\
\text { harapan }\end{array}$ & Valid \\
\hline 6 & Klik tombol simpan & $\begin{array}{l}\text { Penambahan } \\
\text { data di tabel } \\
\text { po }\end{array}$ & $\begin{array}{l}\text { Mengklik tombol } \\
\text { simpan, semua data } \\
\text { tersimpan ke dalam } \\
\text { tabel po dan objek di } \\
\text { form menjadi } \\
\text { nonaktif }\end{array}$ & $\begin{array}{l}\text { Sesuai } \\
\text { harapan }\end{array}$ & Valid \\
\hline 7 & Klik tombol Surat & Menampilkan & Pada saat data & Sesuai & valid \\
\hline
\end{tabular}




\begin{tabular}{|l|l|l|l|l|}
\hline po & surat po & $\begin{array}{l}\text { semua sudah harapan } \\
\text { tersimpan, maka } \\
\text { surat po dapat di } \\
\text { cetak dengan cara } \\
\text { mengklik tombol } \\
\text { surat po }\end{array}$ & \\
\hline
\end{tabular}

\section{E. KESIMPULAN}

Kesimpulan yang dapat ditarik pada program persediaan ini yaitu:

1. Pembuatan laporan persediaan barang dapat dilakukan lebih mudah sehingga mengurangi kemungkinan terjadi kesalahan pada persediaan barang.

2. Memudahkan dalam pengecekan persediaan barang

3. Pengolahan data barang masuk dan barang keluar lebih efektif dan efisien.

4. Data barang masuk dan barang keluar tersimpan di dalam database danmemudahkan dalam pencarian.

\section{DAFTAR PUSTAKA}

Darwati, I. (2018). Metode Waterfall Dalam Perancangan Program Pembelian Pada Toko Furniture, 6(1), 101-106.

Minarni, \& Susanti. (2014). Sistem Informasi Inventory Obat Pada Rumah Sakit Umum Daerah ( Rsud ) Padang. Momentum, 16(1), 103-111.

MT, Y., \& Poerwanta, R. (2013). Perancangan Sistem Inventory Spare Parts Mobil Pada Cv . Auto Parts Toyota Berbasis Aplikasi Java. Jurnal TEKNOIF, 1, 1-5. Retrieved from

https://ejournal.itp.ac.id/index.php/tinform atika/article/view/139/138

Nugroho, A. (2010). Rekaya Perangkat Lunak Berorientasi Objek Dengan Menggunakan Metode USDP (Unified Software Development Process). Yogyakarta: Andi Offset.

Rahadi, A. (2014). BERBASIS KOMPUTER ( Studi Kasus pada Toko Arta Boga ). Adysta Rahadi, 8(2), 2.

Sari, A. O., \& Nuari, E. (2017). Rancang Bangun Sistem Informasi Persediaan Barang Berbasis Web Dengan Metode Fast (Framework For The Applications). Jurnal PILAR Nusa Mandiri, Vol. 13, $N(2), 261-266$.

Sukamto, R. A., \& Shalahuddin, M. (2016). Rekayasa Perangkat Lunak Terstruktur dan Berorientasi Objek. Bandung: Informatika Bandung.

Veza, O., \& Ropianto, M. (2017). PERANCANGAN SISTEM INFORMASI INVENTORY DATA BARANG PADA PT.ANDALAS BERLIAN MOTORS (Studi Kasus: PT Andalas Berlian Motors Bukit Tinggi). Jurnal Teknik Ibnu Sina JT-IBSI, 2(2), 121-134. 